\title{
Correction to: Tracheal and Bronchial Surgery: HJFV
}

Radu Stoica and loan Cordos

\section{Correction to: Tracheal and Bronchial Surgery: HJFV https://doi.org/10.1007/978-3-030-28528-9_23}

The chapter was published with a mistake in references 25 (Rinieria P, Peillona C, Bessoub J-P. National review of use of extracorporeal membrane oxygenation as respiratory support in thoracic surgery excluding lung transplantation)

The same has been updated as:

25. Rinieri P, Peillon C, Bessou J-P. National review of use of extracorporeal membrane oxygenation as respiratory support in thoracic surgery excluding lung transplantation. Eur J Cardio-Thoracic Surg. 2015;21:517-22.

The updated online version of this chapter can be found at https://doi.org/10.1007/978-3-030-28528-9_23 